\title{
Income gradient in health-related quality of life - the role of social networking time
}

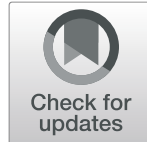

Shaozhe Zhang ${ }^{1^{*}}$ (i) and Wei Xiang ${ }^{2}$

\begin{abstract}
Background: Widening social class discrepancies in health persist in the United States. Although the relationship between social class and health has been well illustrated, the pathways through which social class influences the distribution of health remain unidentified. This study is designed to analyze the income-health relationship by examining the role of social networking time.

Methods: A nationwide sample from the General Social Survey of the United States is adopted for the statistical analysis. The Healthy Days Measures developed by the Centers for Disease Control and Prevention are used to evaluate health-related quality of life in the general population. Social networking time is measured through the number of social evenings respondents spend with neighbors. Individuals' inflation-adjusted family income is used to indicate their income. The relationships between income, social networking time and health-related quality of life are calculated through multiple linear regressions, and the mediation effects of social networking time are further tested by the Sobel test with bootstrapping.

Results: People with a lower income tend to spend more time socializing with their neighbors than those with a higher income. Income is positively associated with health-related quality of life. Respondents who engage more frequently in neighborhood socializing report poorer health-related quality of life. The reproduction of the income gradient in health-related quality of life through social networking time mainly persists in mental health aspects.

Conclusions: This study verifies the positive association between income and health-related quality of life. The results show that people's network ties are affected by their income and confirm the role of social networking time in the reproduction of the income gradient in health-related quality of life.
\end{abstract}

Keywords: Health-related quality of life, Income, Gradient, Social networking time

\section{Introduction}

In recent decades, life expectancy has increased and the mortality rate has decreased, but socioeconomic disparities in health outcomes persist. Social gradients in health, whereby individuals from lower social class backgrounds have poorer health status, higher risk of illness and a shorter life expectancy, have been well documented in existing studies [1-4]. Numerous efforts, such as increased investment in health and health services and the implementation of health promotion policies, have been made to reduce health inequalities; however, substantial evidence indicates that social class disparities in health are widening [5-8]. Income, as a basic indicator of social

\footnotetext{
* Correspondence: szhang0417@foxmail.com

${ }^{1}$ Department of Sociology, Wuhan University, Wuhan 430072, China

Full list of author information is available at the end of the article
}

class, plays a dominant role in the maintenance of people's health [9]. Higher income is related to better health conditions and lower health risks, while lower income means more exposure to health risk factors. How is income related to health, and why is the income gradient in health continuing to widen?

Prior studies on the income-health relationship focus on two sets of issues: the effect of absolute income on health and the association between relative income and health. With regard to the effect of absolute income, money involves access to resources that benefit for health, such as medical services [10], better nutrition [11] and resources embedded in social networks [12]. The relative income aspect mainly concerns the psychosocial pathways of the income gradient in health, as the sense of relative deprivation that derives from income

(c) The Author(s). 2019 Open Access This article is distributed under the terms of the Creative Commons Attribution 4.0 International License (http://creativecommons.org/licenses/by/4.0/), which permits unrestricted use, distribution, and 
differences could have adverse psychosocial consequences [13]. People with lower relative income experience higher risks of mental health disorders, including depression and anxiety [14].

Among all the factors linking income and health, the effect of social networks attracts the most attention. However, the measurements of social networks vary across studies, and social networks are often conceptualized in terms of both functions and structures. The functional conceptualizations include supportive social contacts [15] and the availability of support [16]. As a main source of social support, social networks are considered protective factors of health. The structural aspects of social networks encompass the social ties in which people are embedded [17] and the pathways of network influence [18]. Smith and Christakis [19] reviewed the differences between social support and social networks and found that studies on social support focus on the number of contacts and the helpfulness of those contacts, while analyses of social networks concentrate on the nature and types of ties linking people together, including the closeness of the ties and the relationships of the people embedded in the ties, such as friends, relatives and neighbors. The influence of social networks on health appears uncertain when networks are conceptualized structurally. Different types of social ties are not always supportive of or beneficial for health, as a negative effect of neighborhood connections on mental health has been found [20].

Moreover, although income is positively related to the availability of social support, people of different income levels have distinctive preferences in relation to social network types. A study on the association between income and social network choices shows that people with higher income spend more time with their friends, while those with lower income spend more social networking time with neighbors [21]. Since income impacts people's social networking time with their neighbors and neighborhood connections might be harmful for health, is it possible that neighborhood networks mediate the relationship between income and health and help explain the health inequalities between people with different income levels?

This study extends the current research on the income gradient in health by discussing the possible mediating effect of a typical type of social network: neighborhood ties. Income is considered a social contextual factor influencing people's embeddedness in neighborhood ties. Furthermore, health-related quality of life (HRQoL) is adopted to evaluate people's health outcomes [22-24]. HRQoL is described as people's perceived physical and mental health over time [25], reflecting individuals' subjective feelings of the extent to which health problems influence their daily life. In the context of the epidemiological transition to an era in which non-communicable chronic diseases have become a major risk factor for people's health, HRQoL, which implies a direct linkage to health conditions [26] and subjective assessment of health status, is more reflective of the modern biopsychosocial medical model than objective indicators such as life expectancy and mortality rate [24].

\section{Methods}

Data

The cross-sectional data employed for the statistical analysis were drawn from the General Social Survey (GSS) 2002, 2006, 2010 and 2014 [27]. Launched in 1972, the GSS gathers data on contemporary American society to monitor and explain trends and constants in the attitudes, behaviors, and attributes of the adult population in the United States. With the support of the National Science Foundation, the GSS is conducted by the $\mathrm{Na}$ tional Opinion Research Center (NORC) at the University of Chicago every one or two years with a strict, full-probability sample design, and the response rates range from 70 to $82.4 \%$ [28]. In each survey year, subsamples are randomly selected to answer selected survey questions. HRQoL questions were asked in 2002, 2006, 2010 and 2014, and participants in the subsamples who answered the questions in these four survey years were included in the analysis.

\section{Variables \\ Dependent variables}

The dependent variable, HRQoL, was assessed by the "Healthy Days Measures" developed by the Centers for Disease Control and Prevention (CDC) [29]. These measures include four questions on general health, the number of physically unhealthy days, the number of mentally unhealthy days, and the number of days with activity limitations. General health is assessed with the question "Would you say that in general your health is excellent, very good, good, fair or poor?" Responses range from 5 to 1 . The number of days of poor physical health, poor mental health and activity limitations are assessed, respectively, with the questions "Now, thinking about your physical health, which includes physical illness and injury, how many days during the past 30 days was your physical health not good?" "Now, thinking about your mental health, which includes stress, depression, and problems with emotions, how many days during the past 30 days was your mental health not good?" and "During the past 30 days, approximately how many days did poor physical or mental health keep you from doing your usual activities, such as self-care, work, or recreation?". The validity of the Healthy Days Measures for measuring HRQoL was confirmed by comparing their outcomes with those of the SF-36 in two previous studies using special samples and statewide samples in the US [30, 
31]. The reliability of the Healthy Days Measures was also shown to be excellent in a retest study carried out in the US [32].

\section{Independent variable}

The independent variable in this analysis was income. The family real income variable (REALINC) in the GSS data, which is inflation-adjusted constant dollars [33], was used in the analysis. Family income was used rather than the respondent's income because in the GSS, family income measures income from all sources, while the respondent's income is the earnings from a single occupation [33]. The income variable was log transformed in the models.

\section{Mediation variable}

Social networking time served as the possible mediator in illustrating the reproductive path of income gradients in HRQoL, and it was represented by the number of social evenings the respondents spent with their neighbors per year. This was evaluated with the question "How often do you spend a social evening with someone who lives in your neighborhood?" in the GSS. The original categorical frequencies were transferred into numeric days per year by assigning "almost daily" a value of 300 , "once a year" a value of 1 and "never" a value of 0 . A value of 4 was assigned to the "several" response. Thus, "several times a week" was coded as $208(4 \times 52)$, "several times a month" as $48(4 \times 12)$ and several times year as $4(4 \times 1)[21,34]$.

\section{Control variables}

Sociodemographic variables that have been confirmed to affect HRQoL were employed as control variables, including age, sex, race, marital status, place of living and working status. Number of children and geographical mobility (whether the respondent had lived in the same city since age 16) were further controlled to assess the robustness of the relationship between income and social networking time with neighbors. Dummy variables for the GSS survey year were also included because the size of people's social networks declines over time [35].

\section{Analytical strategies}

The objectives of this research were twofold. First, the study examined the relationships between income, social networking time and HRQoL. Then, the reproduction of health inequalities through social networking time was tested based on the four criteria for mediation paths proposed by Baron and Kenny [36] (Fig. 1): (1) the coefficient of path a is significant in identifying the effect of the independent variable (IV) on the mediating variable (MV); (2) the MV is significantly related to the dependent variable (DV) net of the IV (path b); (3) the

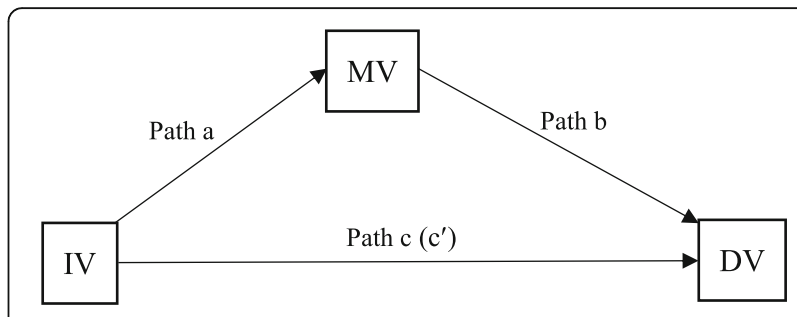

Fig. 1 Mediation effect paths

significant direct association (path c) between the IV and the DV is confirmed; and (4) the association between the IV and the DV is weakened when the MV is controlled (path c').

Stata/MP 14.2 for Mac was used to carry out the statistical analysis. Multiple linear regression models were formulated to evaluate the associations among income, social networking time and HRQoL. First, the way that individuals' income predicts social networking time with neighbors was tested. Two models were constructed for this question. Sociodemographic control variables were included in Model 1, and variables of geographic mobility and number of children were added to Model 2 based on Model 1. Then, the relationship between income and HRQoL was calculated, and social networking time was further incorporated into the models. Eight models were formulated to assess the relationships. In Models 3, 5, 7 and 9 , sociodemographic variables were controlled, and in Models 4, 6, 8 and 10, the indicator of social networking time was included. Third, the possible mediation effect of social networking time was identified using the Sobel mediation test with the bootstrapping process, which overcomes the assumption of a normal distribution of the classical Sobel mediation test [37].

Although social networking time and HRQoL indicators were non-normally distributed, the large sample size (more than 500) justified the use of linear regression [38]. The robustness of the $p$ values (Appendix) was confirmed via bootstrapping process [39].

\section{Results}

\section{Descriptive statistics}

The total number of participants with valid responses to the questions on both HRQoL and social networking time in 2002, 2006, 2010 and 2014 was 3330. Table 1 presents the descriptions of all variables in the analysis. The average numbers of days of poor physical and mental health were less than 4 per month, and the number of days of activity limitation was about 1.5 each month. The respondents spent several evenings per month with their neighbors on average.

Table 2 presents the distributions of the respondents' social networking time with neighbors, income and HRQoL. Participants who were female, white, married 
Table 1 Descriptions of the Variables

\begin{tabular}{|c|c|c|c|c|c|}
\hline Variables & Obs & Mean/percent & SD & Value & Value label \\
\hline \multicolumn{6}{|l|}{ Dependent variables } \\
\hline Days of poor physical health & 3322 & 2.581 & 6.188 & $0-30$ & \\
\hline Days of poor mental health & 3330 & 3.297 & 6.964 & $0-30$ & \\
\hline Days of activity limitation & 3325 & 1.230 & 4.062 & $0-30$ & \\
\hline Assessment of general health & 3329 & 3.652 & 1.015 & $1-5$ & $1=$ poor, $5=$ excellent \\
\hline \multicolumn{6}{|l|}{ Independent variable } \\
\hline Income (\$) & 3042 & $38,281.08$ & $33,832.01$ & $236.5-144,502.7$ & \\
\hline \multicolumn{6}{|l|}{ Mediator } \\
\hline Social networking time & 3330 & 54.972 & 91.971 & $0-300$ & \\
\hline \multicolumn{6}{|l|}{ Control variables } \\
\hline Age & 3320 & 42.898 & 13.308 & $18-88$ & \\
\hline Sex (male) & 3330 & $48.02 \%$ & - & 0,1 & $\begin{array}{l}1=\text { male } \\
0=\text { female }\end{array}$ \\
\hline Race (white) & 3330 & $75.56 \%$ & - & 0,1 & $\begin{array}{l}1=\text { white } \\
0=\text { non-white }\end{array}$ \\
\hline Marital status (married) & 3329 & $47.10 \%$ & - & 0,1 & $\begin{array}{l}1=\text { married } \\
0=\text { not married }\end{array}$ \\
\hline Working status (working) & 3330 & $97.36 \%$ & - & 0,1 & $1=$ working, $0=$ not working \\
\hline Geographic mobility (same city since age 16) & 3325 & $39.01 \%$ & - & 0,1 & $\begin{array}{l}1=\text { same city since age } 16 \\
0=\text { not the same city }\end{array}$ \\
\hline Number of children & 3327 & 1.597 & 1.483 & $0-8$ & \\
\hline Place of living (urban) & 3330 & $89.13 \%$ & - & 0,1 & $1=$ urban, $0=$ rural \\
\hline
\end{tabular}

Table 2 Descriptive results of social networking time, income and HRQOL

\begin{tabular}{|c|c|c|c|c|c|c|c|c|c|c|c|c|}
\hline \multirow[t]{2}{*}{ Variables } & \multicolumn{2}{|c|}{$\begin{array}{l}\text { Social } \\
\text { networking time }\end{array}$} & \multicolumn{2}{|c|}{$\begin{array}{l}\text { Family income } \\
\text { (1000 dollars) }\end{array}$} & \multicolumn{2}{|c|}{$\begin{array}{l}\text { Days of poor } \\
\text { mental health }\end{array}$} & \multicolumn{2}{|c|}{$\begin{array}{l}\text { Days of poor } \\
\text { physical health }\end{array}$} & \multicolumn{2}{|c|}{$\begin{array}{l}\text { Days of activity } \\
\text { limitations }\end{array}$} & \multicolumn{2}{|c|}{$\begin{array}{l}\text { Assessment of general } \\
\text { health }\end{array}$} \\
\hline & mean & t-test & mean & t-test & mean & t-test & mean & t-test & mean & t-test & mean & t-test \\
\hline \multicolumn{13}{|l|}{ Sex } \\
\hline Female & 50.269 & $-9.794^{* * *}$ & 34.672 & $-7.509^{* * *}$ & 3.704 & $0.847^{* * *}$ & 2.832 & $0.521^{* *}$ & 1.334 & 0.217 & 3.639 & -0.028 \\
\hline Male & 60.063 & & 42.181 & & 2.857 & & 2.311 & & 1.117 & & 3.667 & \\
\hline \multicolumn{13}{|l|}{ Race } \\
\hline Non-white & 60.889 & $7.832^{* *}$ & 28.077 & $-13.478^{* * *}$ & 3.131 & -0.22 & 2.425 & -0.207 & 1.157 & -0.097 & 3.557 & $-0.127^{* * *}$ \\
\hline White & 53.058 & & 41.555 & & 3.351 & & 2.632 & & 1.254 & & 3.683 & \\
\hline \multicolumn{13}{|l|}{ Marital status } \\
\hline Non-married & 69.119 & $30.007^{* * *}$ & 26.973 & $-23.821^{* * *}$ & 3.857 & $1.186^{* * *}$ & 2.796 & $0.454^{* *}$ & 1.439 & $0.443^{* * *}$ & 3.615 & $-0.078^{* *}$ \\
\hline Married & 39.112 & & 50.795 & & 2.671 & & 2.342 & & 0.996 & & 3.693 & \\
\hline \multicolumn{13}{|l|}{ Working status } \\
\hline Not working & 38.841 & $-16.569^{*}$ & 37.158 & -1.152 & 8.432 & $5.274^{* * *}$ & 10.773 & $8.414^{* * *}$ & 8.432 & $7.398^{* * *}$ & 3.057 & $-0.611^{* * *}$ \\
\hline Working & 55.41 & & 38.310 & & 3.158 & & 2.358 & & 1.034 & & 3.668 & \\
\hline \multicolumn{13}{|l|}{ Place of living } \\
\hline Rural & 53.68 & -1.453 & 29.776 & $-9.568^{* * *}$ & 3.575 & 0.311 & 2.756 & 0.195 & 1.222 & -0.009 & 3.434 & $-0.245^{* * *}$ \\
\hline Urban & 55.13 & & 39.344 & & 3.263 & & 2.56 & & 1.231 & & 3.679 & \\
\hline
\end{tabular}


and not working spent fewer social evenings with their neighbors. Female, non-white, and non-married respondents and those living in rural areas had a lower family income. Male and married respondents reported better HRQoL.

\section{Income and social networking time}

The association between income and social networking time is displayed in Table 3. In Model 1, a significant negative association was captured between the respondent's income and the number of social evenings spent with neighbors net of age, sex, marital status, working status and place of living. Geographical mobility and number of children were controlled in Model 2 to check the robustness of the association between income and social networking time. The result indicated that people with a higher income spent less time in their neighborhood socializing than those with a lower income.

Table 3 Regression results of the association of income and social networking time ${ }^{a}$

\begin{tabular}{|c|c|c|}
\hline Variables & Model 1 & Model 2 \\
\hline \multirow[t]{2}{*}{ Income } & $-0.133^{* * *}$ & $-0.137^{* * *}$ \\
\hline & $(1.919)$ & $(1.944)$ \\
\hline \multirow[t]{2}{*}{ Age } & $-0.621^{* * *}$ & $-0.603^{* * *}$ \\
\hline & $(0.765)$ & $(0.775)$ \\
\hline \multirow[t]{2}{*}{$\mathrm{Age}^{2}$} & $0.534^{* * *}$ & $0.528^{* * *}$ \\
\hline & $(0.008)$ & $(0.008)$ \\
\hline \multirow[t]{2}{*}{ Sex (male) } & $0.063^{* * *}$ & $0.063^{* * *}$ \\
\hline & (3.238) & $(3.247)$ \\
\hline \multirow[t]{2}{*}{ Race (white) } & 0.007 & 0.003 \\
\hline & $(3.870)$ & $(3.911)$ \\
\hline \multirow[t]{2}{*}{ Marital status (married) } & $-0.087^{* * *}$ & $-0.080^{* * *}$ \\
\hline & $(3.567)$ & $(3.676)$ \\
\hline \multirow[t]{2}{*}{ Working status (working) } & 0.024 & 0.024 \\
\hline & $(10.258)$ & $(10.262)$ \\
\hline \multirow[t]{2}{*}{ Place of living (urban) } & 0.009 & 0.008 \\
\hline & $(5.170)$ & $(5.182)$ \\
\hline \multirow[t]{2}{*}{ Geographical mobility (same city since age 16) } & & 0.003 \\
\hline & & (3.346) \\
\hline \multirow[t]{2}{*}{ Number of children } & & -0.032 \\
\hline & & $(1.214)$ \\
\hline Year fixed effects ${ }^{b}$ & yes & yes \\
\hline N & 3037 & 3029 \\
\hline$R^{2}$ & 0.070 & 0.071 \\
\hline
\end{tabular}

\section{Income, social networking time and HRQoL}

Among the HRQoL measures, income was negatively related to the number of days of poor health and positively related to the general assessment of health (Table 4), reflecting the beneficial role of income in HRQoL. Model 3 and Model 4 calculated how income was related to the respondent's number of days of poor mental health and the effect of social networking time with neighbors. The result indicated a significant positive association between social networking time and the number of days of poor mental health. Female respondents had more days of poor mental health than male respondents, and white respondents had more days of poor mental health than non-white respondents. In Model 6, respondents who were more engaged in socializing with neighbors had more days of poor physical health, which was similar to the relationship between social networking time and mental health. The effect of the respondent's social networking time on the number of days of activity limitations and on the general assessment of health was not significant, as shown in Model 8 and Model 10.

\section{Mediation effect of social networking time}

Model 4 and Model 6 showed that social networking time was significantly related to the respondent's number of days of poor mental and physical health. Therefore, the mediating effect of social networking time on the impact of income on these two indicators of HRQoL was further tested through the Sobel mediation test with the bootstrapping procedure.

In Model 1, income was significantly related to the respondent's social networking time with neighbors, which met the requirement of path a $(\beta=-0.133, p<$ 0.001). In Model 3 and Model 4, the significant association between income and the respondent's number of days of poor mental health persisted both with and without the adjustment of social networking time. This fulfilled path $\mathrm{c}(\beta=-0.127, p<0.001)$ and path $\mathrm{c}^{\prime}(\beta=-$ $0.118, p<0.001)$, and the magnitude of income decreased when social networking time was controlled (Fig. 2). The Sobel mediation test indicated a significant indirect effect (Sobel test value $=-0.064, p<0.01$ ), and the result of the bootstrap procedure corroborated the Sobel test result: the 95\% bias-corrected CI did not contain zero, indicating that the association of income and the respondent's mental health was mediated by social networking time.

In Model 5 and Model 6, the coefficients of income and social networking time satisfied the requirement of mediation effect paths; however, the result of the Sobel test was not significant, suggesting that social networking time may not be a mediator between income and people's physical health. 
Table 4 Regression results of income, social networking time and $\mathrm{HRQOL}^{\mathrm{a}}$

\begin{tabular}{|c|c|c|c|c|c|c|c|c|}
\hline \multirow[t]{2}{*}{ Variables } & \multicolumn{2}{|c|}{ Days of poor mental health } & \multicolumn{2}{|c|}{ Days of poor physical health } & \multicolumn{2}{|c|}{ Days of activity limitations } & \multicolumn{2}{|c|}{ General assessment of health } \\
\hline & Model 3 & Model 4 & Model 5 & Model 6 & Model 7 & Model 8 & Model 9 & Model 10 \\
\hline \multirow[t]{2}{*}{ Income } & $-0.127^{* * *}$ & $-0.118^{* * *}$ & $-0.106^{* * *}$ & $-0.102^{* * *}$ & $-0.069^{* * *}$ & $-0.065^{* *}$ & $0.219^{* * *}$ & $0.223^{* * *}$ \\
\hline & $(0.146)$ & $(0.147)$ & $(0.130)$ & $(0.131)$ & $(0.083)$ & $(0.084)$ & $(0.021)$ & $(0.021)$ \\
\hline \multirow[t]{2}{*}{ Place of living (urban) } & 0.002 & 0.002 & 0.016 & 0.016 & 0.012 & 0.012 & $0.049^{* *}$ & $0.049^{* *}$ \\
\hline & $(0.395)$ & $(0.394)$ & $(0.351)$ & $(0.351)$ & $(0.224)$ & $(0.224)$ & $(0.057)$ & $(0.057)$ \\
\hline \multirow[t]{2}{*}{ Age } & 0.082 & 0.124 & -0.010 & 0.013 & -0.043 & -0.026 & $-0.443^{* * *}$ & $-0.424^{* * *}$ \\
\hline & $(0.058)$ & $(0.059)$ & $(0.052)$ & $(0.052)$ & $(0.033)$ & $(0.033)$ & $(0.008)$ & $(0.009)$ \\
\hline \multirow[t]{2}{*}{$\mathrm{Age}^{2}$} & -0.141 & -0.177 & 0.066 & 0.046 & 0.064 & 0.050 & $0.354^{* *}$ & $0.338^{* *}$ \\
\hline & $(0.001)$ & $(0.001)$ & $(0.001)$ & $(0.001)$ & $(0.0004)$ & $(0.0004)$ & $(0.0001)$ & $(0.0001)$ \\
\hline \multirow[t]{2}{*}{ Sex (male) } & $-0.054^{* *}$ & $-0.058^{* *}$ & -0.026 & -0.028 & -0.018 & -0.020 & -0.012 & -0.014 \\
\hline & $(0.247)$ & $(0.247)$ & $(0.220)$ & $(0.220)$ & $(0.140)$ & $(0.141)$ & $(0.036)$ & $(0.036)$ \\
\hline \multirow[t]{2}{*}{ Race (white) } & $0.066^{* * *}$ & $0.065^{* * *}$ & 0.032 & 0.032 & 0.031 & 0.031 & 0.024 & 0.024 \\
\hline & $(0.295)$ & $(0.295)$ & $(0.263)$ & $(0.262)$ & $(0.168)$ & $(0.168)$ & $(0.043)$ & $(0.043)$ \\
\hline \multirow[t]{2}{*}{ Marital status (married) } & -0.027 & -0.021 & 0.005 & 0.008 & -0.024 & -0.022 & -0.031 & -0.029 \\
\hline & $(0.272)$ & $(0.272)$ & $(0.242)$ & $(0.243)$ & $(0.154)$ & $(0.155)$ & $(0.040)$ & $(0.040)$ \\
\hline \multirow[t]{2}{*}{ Working status (working) } & $-0.116^{* * *}$ & $-0.117^{* * *}$ & $-0.207^{* * *}$ & $-0.208^{* * *}$ & $-0.285^{* * *}$ & $-0.285^{* * *}$ & $0.088^{* * *}$ & $0.087^{* * *}$ \\
\hline & $(0.783)$ & $(0.781)$ & $(0.695)$ & $(0.695)$ & $(0.444)$ & $(0.444)$ & $(0.115)$ & $(0.115)$ \\
\hline \multirow[t]{2}{*}{ Social networking time } & & $0.067^{* * *}$ & & $0.037^{*}$ & & 0.026 & & 0.030 \\
\hline & & $(0.001)$ & & $(0.001)$ & & $(0.001)$ & & $(0.0002)$ \\
\hline Year fixed effects & yes & yes & yes & yes & yes & yes & yes & yes \\
\hline N & 3037 & 3037 & 3030 & 3030 & 3032 & 3032 & 3036 & 3036 \\
\hline$R^{2}$ & 0.045 & 0.049 & 0.059 & 0.061 & 0.092 & 0.093 & 0.063 & 0.064 \\
\hline
\end{tabular}

\section{Discussion}

This study focuses on the income gradient in health and how it is reproduced through people's social networking time in the United States. A positive association between income and HRQoL is captured, and the inequalities in HRQoL reproduced through neighborhood socializing mainly exist in relation to mental health.

The statistical results demonstrate that people with higher income generally have higher HRQoL, which has been well supported in existing studies [40]. The income gradient in HRQoL derives from various inequalities related to health, including differentiated access to healthcare services and unbalanced allocation of health-related resources, as well as distinctions in health-related lifestyles across social classes.

The study also confirms the negative association between income and social networking time with neighbors. This negative association could be explained by people's structural embeddedness and their access to resources. Prior analyses show that people with abundant resources tend to be less dependent on others [41, 42]. Thus, people with lower income and limited access to resources may spend more time socializing to obtain social support. A psychological experiment studying patterns of nonverbal displays of disengagement and engagement among participants with varied socioeconomic statuses suggests that

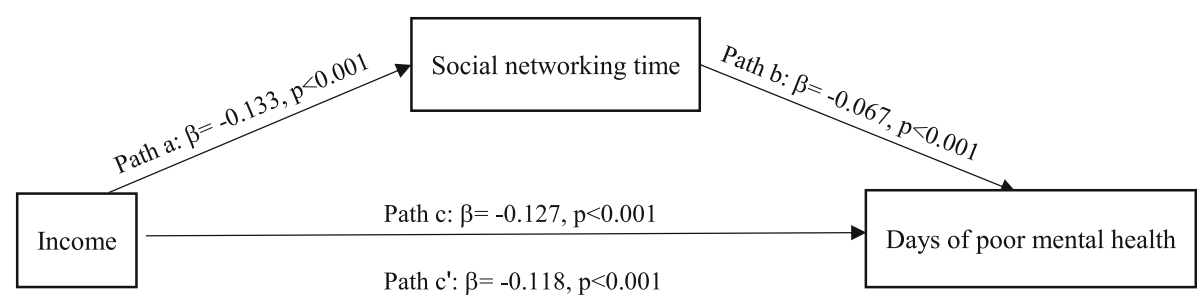

Fig. 2 Mediation effect of social networking time on income and mental health 
people of higher socioeconomic status display more disengagement cues in social contact than people from lower classes [43]. This is in line with the study of Bianchi \& Vohs [21], which indicates that people from lower classes tend to spend more time socializing with neighbors than with relatives and friends, as neighbors may provide more immediate instrumental support based on geographic proximity than friends and relatives.

The reproduction of health disparities is examined through the mediating role of social networking time in the relationship between income and HRQoL. The reproduced inequalities are probably more related to mental HRQoL than other aspects, as neighborhood connections impact mental health more directly [44]. Social networks and ties are major sources of social support, which is beneficial for the maintenance of health, but the helpfulness of networks is uncertain. Several existing studies examining mental health inequalities across classes demonstrate that social connections may paradoxically increase the level of mental illness symptoms among less privileged groups [45-47]. From the psychosocial perspective, the sense of relative deprivation arising from social networking with neighbors may harm people with lower income. Reciprocity and mutual instrumental support are the dominant basis of the establishment of neighborhood connections. However, those who are most in need of support are often the least likely to receive it and must bear a disproportionate cost of involvement [48]. People engaging in such relationships with limited resources may face greater difficulty in responding to others' needs. Therefore, for people with lower income with limited access to resources, reciprocal neighborhood connections mean more psychological costs as a result of the sense of indebtedness. Finally, the contextual characteristics of social networks cannot be ignored in analyzing the reproduction of income gradients in HRQoL through neighborhood ties, as "interpersonal relationships occur within broader social contexts" [49]. People with lower income are more dependent on collective resources in the neighborhood, and neighborhood deprivation may have a negative effect on their mental health. The impact of social context on mental health is indicated by Durkheim in the illustration of the relationship between surrounding social climate and suicide rates [50]. Empirical studies on neighborhood deprivation and mental health indicate that neighborhood attachment is associated with higher reporting of common mental disorders [47]. The sense of relative deprivation, individual neighborhood socializing cost and a comparatively disadvantaged neighborhood environment may jointly or separately result in the reproduction of the income gradient in HRQoL.
This study offers two major contributions. Drawing insights from previous studies on differences in social networks and social support, this study shows that the supportiveness of social networks is uncertain and that social networks are not always helpful and beneficial for people's health. It further suggests that the social networking time differences between people with different income levels could be considered one of the mechanisms of social class inequality in health.

The study should be viewed in light of several limitations. First, though the significant association between income and social networking time is confirmed, it is uncertain whether neighborhood networking affects people's income. Although working status is controlled in the analytical models, it is still possible that people who are more engaged in neighborhood socializing are less concentrated on other money-making activities and thus earn less money. Nonetheless, this study maps out people's social network preferences reconciled with their social positions as a product of their structural embeddedness and surrounding social world. Second, the results indicate that people's HRQoL is influenced by their social networking

Table 5 Bootstrap check of income and social networking time

\begin{tabular}{|c|c|c|}
\hline Variables & Model 11 & Model 12 \\
\hline \multirow[t]{2}{*}{ Income } & $-0.133^{* * *}$ & $-0.137^{* * *}$ \\
\hline & $(2.141)$ & $(2.295)$ \\
\hline \multirow[t]{2}{*}{ Age } & $-0.621^{* * *}$ & $-0.603^{* * *}$ \\
\hline & $(0.842)$ & $(0.859)$ \\
\hline \multirow[t]{2}{*}{$\mathrm{Age}^{2}$} & $0.534^{* * *}$ & $0.528^{* * *}$ \\
\hline & $(0.009)$ & $(0.009)$ \\
\hline \multirow[t]{2}{*}{ Sex (male) } & $0.063^{* * *}$ & $0.063^{* * *}$ \\
\hline & $(3.277)$ & $(3.234)$ \\
\hline \multirow[t]{2}{*}{ Race (white) } & 0.007 & 0.003 \\
\hline & (3.894) & $(4.108)$ \\
\hline \multirow[t]{2}{*}{ Marital status (married) } & $-0.087^{* * *}$ & $-0.080^{* * *}$ \\
\hline & $(3.657)$ & $(3.499)$ \\
\hline \multirow[t]{2}{*}{ Working status (working) } & 0.024 & 0.024 \\
\hline & $(9.112)$ & $(9.324)$ \\
\hline \multirow[t]{2}{*}{ Place of living (urban) } & 0.009 & 0.008 \\
\hline & $(4.789)$ & $(5.107)$ \\
\hline \multirow[t]{2}{*}{ Geographical mobility (same city since age 16) } & & 0.003 \\
\hline & & $(3.466)$ \\
\hline \multirow[t]{2}{*}{ Number of children } & & -0.032 \\
\hline & & $(1.237)$ \\
\hline Year fixed effects & yes & yes \\
\hline N & 3037 & 3029 \\
\hline$R^{2}$ & 0.070 & 0.071 \\
\hline
\end{tabular}


Table 6 Bootstrap check of income, social networking time and HRQOL

\begin{tabular}{|c|c|c|c|c|c|c|c|c|}
\hline \multirow[t]{2}{*}{ Variables } & \multicolumn{2}{|c|}{ Days of poor mental health } & \multicolumn{2}{|c|}{ Days of poor physical health } & \multicolumn{2}{|c|}{ Days of activity limitations } & \multicolumn{2}{|c|}{ General assessment of health } \\
\hline & Model 13 & Model 14 & Model 15 & Model 16 & Model 17 & Model 18 & Model 19 & Model 20 \\
\hline \multirow[t]{2}{*}{ Income } & $-0.127^{* * *}$ & $-0.118^{* * *}$ & $-0.106^{* * *}$ & $-0.102^{* * *}$ & $-0.069^{*}$ & $-0.065^{*}$ & $0.219^{* * *}$ & $0.223^{* * *}$ \\
\hline & $(0.164)$ & $(0.165)$ & $(0.139)$ & $(0.152)$ & $(0.112)$ & $(0.109)$ & $(0.022)$ & $(0.023)$ \\
\hline \multirow[t]{2}{*}{ Place of living (urban) } & 0.002 & 0.002 & 0.016 & 0.016 & 0.012 & 0.012 & $0.049^{* *}$ & $0.049^{* *}$ \\
\hline & $(0.389)$ & $(0.392)$ & $(0.334)$ & $(0.352)$ & $(0.233)$ & $(0.226)$ & $(0.057)$ & $(0.060)$ \\
\hline \multirow[t]{2}{*}{ Age } & 0.082 & 0.124 & -0.010 & 0.013 & -0.043 & -0.026 & $-0.443^{* * *}$ & $-0.424^{* * *}$ \\
\hline & $(0.061)$ & $(0.061)$ & $(0.061)$ & $(0.057)$ & $(0.036)$ & $(0.036)$ & $(0.009)$ & $(0.009)$ \\
\hline \multirow[t]{2}{*}{$\mathrm{Age}^{2}$} & -0.141 & -0.177 & 0.066 & 0.046 & 0.064 & 0.050 & $0.354^{* *}$ & $0.338^{* *}$ \\
\hline & $(0.001)$ & $(0.001)$ & $(0.001)$ & $(0.001)$ & $(0.0004)$ & $(0.0004)$ & $(0.0001)$ & $(0.0001)$ \\
\hline \multirow[t]{2}{*}{ Sex (male) } & $-0.054^{* *}$ & $-0.058^{* * *}$ & -0.026 & -0.028 & -0.018 & -0.020 & -0.012 & -0.014 \\
\hline & $(0.241)$ & $(0.239)$ & $(0.234)$ & $(0.218)$ & $(0.153)$ & $(0.142)$ & $(0.036)$ & $(0.035)$ \\
\hline \multirow[t]{2}{*}{ Race (white) } & $0.066^{* * *}$ & $0.065^{* * *}$ & 0.032 & 0.032 & 0.031 & 0.031 & 0.024 & 0.024 \\
\hline & $(0.287)$ & $(0.297)$ & $(0.244)$ & $(0.260)$ & $(0.154)$ & $(0.153)$ & $(0.044)$ & $(0.044)$ \\
\hline \multirow[t]{2}{*}{ Marital status (married) } & -0.027 & -0.021 & 0.005 & 0.008 & -0.024 & -0.022 & -0.031 & -0.029 \\
\hline & $(0.283)$ & $(0.271)$ & $(0.232)$ & $(0.237)$ & $(0.160)$ & $(0.164)$ & $(0.041)$ & $(0.041)$ \\
\hline \multirow[t]{2}{*}{ Working status (working) } & $-0.116^{* * *}$ & $-0.117^{* * *}$ & $-0.207^{* * *}$ & $-0.208^{* * *}$ & $-0.285^{* * *}$ & $-0.285^{* * *}$ & $0.088^{* * *}$ & $0.087^{* * *}$ \\
\hline & (1.158) & $(1.244)$ & $(1.413)$ & $(1.412)$ & $(1.346)$ & $(1.304)$ & $(0.128)$ & $(0.121)$ \\
\hline \multirow[t]{2}{*}{ Social networking time } & & $0.067^{* *}$ & & 0.037 & & 0.026 & & 0.030 \\
\hline & & $(0.002)$ & & $(0.001)$ & & $(0.001)$ & & $(0.002)$ \\
\hline Year fixed effects & yes & yes & yes & yes & yes & yes & yes & yes \\
\hline N & 3037 & 3037 & 3030 & 3030 & 3032 & 3032 & 3036 & 3036 \\
\hline$R^{2}$ & 0.045 & 0.049 & 0.059 & 0.061 & 0.092 & 0.093 & 0.063 & 0.064 \\
\hline
\end{tabular}

Standardized beta coefficients; standard errors in parentheses

${ }^{*} p<0.05,{ }^{* *} p<0.01,{ }^{* * * *} p<0.001$

time, and the reverse is also possible; that is, people of poorer health status have fewer opportunities to participate in activities other than neighborhood socializing. Finally, income is used as the indicator of people's access to resources, but the neighborhood characteristics that affect the availability of resources are not included in this analysis. Therefore, multilevel models with more detailed neighborhood features are needed in future related studies.

\section{Conclusions}

This study analyzes the income-health relationship and how it is mediated through people's social networking time based on a national-level representative sample from the GSS. The structure and nature of people's social networks are associated with their structural embeddedness and contextual characteristics. The test of the mediation effect of social networking time on the relationship between income and health shows that neighborhood socializing may influence people's mental health as a result of the sense of relative deprivation and the obligatory reciprocity entailed in neighborhood ties. This finding confirms the unequal distribution of HRQoL among people with different income levels and verifies its reproduction through neighborhood social ties.

\section{Appendix}

Bootstrap check of multiple linear regressions

With respect to the non-normal distribution of social networking time with neighbors and number of days with various health conditions, the significance of multiple linear regressions was checked using bootstrap methods with no distribution assumptions (Tables 5 and 6).

There is no change in the $p$ value of income in the bootstrap results between Table 5 and Table 3 in the relationship between income and social networking time. In Table 6, the association between social networking time and mental health is significant at the 99\% level in Model 14. The effect of social networking time on physical health is not significant at the 95\% level in Model 16. The significance level of the relationship between income and days of activity limitations changes from $99.9 \%$ in Model 7 and 99\% in Model 8 to 95\% in Models 17 and 18. 


\section{Abbreviations}

CDC: Centers for Disease Control and Prevention; GSS: General Social Survey; HRQOL: Health-related quality of life

\section{Acknowledgements}

We would like to thank the two anonymous reviewers for their helpful comments and suggestions on the manuscript.

\section{Funding}

Not applicable.

\section{Availability of data and materials}

The datasets generated and/or analyzed during the current study are available in the General Social Survey, http://gss.norc.org.

\section{Authors' contributions}

SZS illustrated the concept of social networks and the differences between social networks and social supports; documented, analyzed and interpreted the data; and was the major contributor in writing the manuscript. WX provided the relevant background information of the study and interpreted the concept of health-related quality of life. Both authors read and approved the final manuscript

\section{Ethics approval and consent to participate}

Not applicable.

\section{Consent for publication}

Not applicable.

\section{Competing interests}

The authors declare that they have no competing interests.

\section{Publisher's Note}

Springer Nature remains neutral with regard to jurisdictional claims in published maps and institutional affiliations.

\section{Author details}

${ }^{1}$ Department of Sociology, Wuhan University, Wuhan 430072, China. ${ }^{2}$ Office of Medical Affairs, Union Hospital, Tongji Medical College, Huazhong University of Science and Technology, Wuhan 430022, China.

Received: 18 October 2018 Accepted: 25 February 2019

Published online: 15 March 2019

\section{References}

1. Mackenbach JP, Stirbu I, Roskam AJR, Schaap MM, Menvielle G, Leinsalu M, Kunst AE. Socioeconomic inequalities in health in 22 European countries. N Engl J Med. 2008;358(23):2468-81.

2. Eikemo TA, Huisman M, Bambra C, Kunst AE. Health inequalities according to educational level in different welfare regimes: a comparison of 23 European countries. Sociol Health IIIn. 2008;30(4):565-82.

3. Bor J, Cohen GH, Galea S. Population health in an era of rising income inequality: USA, 1980-2015. Lancet. 2017;389(10077):1475-90

4. Hu Y, van Lenthe FJ, Borsboom GJ, et al. Trends in socioeconomic inequalities in self-assessed health in 17 European countries between 1990 and 2010. J Epidemiol Community Health. 2016;0:1-9.

5. Lubetkin El, Jia H, Franks P, et al. Relationship among sociodemographic factors, clinical conditions, and health-related quality of life: examining the EQ-5D in the US general population. Qual Life Res. 2005:14(10):2187-96.

6. Strand BH, Grøholt EK, Steingrímsdóttir ÓA, Blakely T, Graff-Iversen S, Næss $\varnothing$. Educational inequalities in mortality over four decades in Norway: prospective study of middle aged men and women followed for cause specific mortality, 1960-2000. BMJ. 2010;340:c654.

7. Cutler DM, Lange F, Meara E, Richards-Shubik S, Ruhm CJ. Rising educational gradients in mortality: the role of behavioral risk factors. J Health Econ. 2011;30(6):1174-87.

8. Centers for Disease Control and Prevention. Strategies for reducing health disparities-selected CDC-sponsored interventions. United States MMWR. 2016;65(1):1-69.

9. Marmot M. The influence of income on health: views of an epidemiologist. Health Aff. 2002;21(2):31-46.
10. Luo J, Zhang X, Jin C, Wang D. Inequality of access to health care among the urban elderly in northwestern China. Health Policy. 2009;93(2-3):111-7.

11. Casey PH, Szeto K, Lensing S, Bogle M, Weber J. Children in foodinsufficient, low-income families: prevalence, health, and nutrition status. Arch Pediatr Adolesc Med. 2001;155(4):508-14.

12. Heritage Z, Wilkinson RG, Grimaud O, Pickett KE. Impact of social ties on self reported health in France: is everyone affected equally? BMC Public Health. 2008;8(1):243.

13. Wilkinson RG. Unhealthy societies - the afflictions of inequality. London: Routledge; 1996.

14. Eibner CE, Sturm R, Gresenz CR. Does relative deprivation predict the need for mental health services? J Ment Health Policy Econ. 2004;7(4): $167-75$.

15. Hawkley LC, Hughes ME, Waite LJ, Masi CM, Thisted RA, Cacioppo JT. From social structural factors to perceptions of relationship quality and loneliness: the Chicago health, aging, and social relations study. J Gerontol Ser B Psychol Sci Soc Sci. 2008;63(6):S375-84.

16. Ashida S, Heaney CA. Differential associations of social support and social connectedness with structural features of social networks and the health status of older adults. J Aging Health. 2008;20(7):872-93.

17. Rosenquist JN, Fowler JH, Christakis NA. Social network determinants of depression. Mol Psychiatry. 2011;16(3):273-81.

18. Onnela JP, Christakis NA. Spreading paths in partially observed social networks. Phys Rev E. 2012;85(3):036106.

19. Smith KP, Christakis NA. Social networks and health. Annu Rev Sociol. 2008; 34:405-29.

20. Caughy MOB, O'Campo PJ, Muntaner C. When being alone might be better: neighborhood poverty, social capital, and child mental health. Soc Sci Med. 2003;57(2):227-37.

21. Bianchi EC, Vohs KD. Social class and social worlds: income predicts the frequency and nature of social contact. Soc Psychol Personal Sci. 2016;7(5): $479-86$.

22. Menati W, Baghbanian A, Asadi-Lari M, Moazen J, Menati R, Sohrabivafa M, et al. Health-related quality of life and socioeconomic status: inequalities among adults in west of Iran. Iran Red Crescent Med J. 2017;19(7):e55571.

23. Rajmil L, Herdman M, Ravens-Sieberer U, Erhart M, Alonso J. Socioeconomic inequalities in mental health and health-related quality of life (HRQOL) in children and adolescents from 11 European countries. Int J Public Health. 2014;59(1):95-105.

24. Tan Z, Shi F, Zhang H, Li N, Xu Y, Liang Y. Household income, income inequality, and health-related quality of life measured by the EQ-5D in Shaanxi, China: a cross-sectional study. Int J Equity Health. 2018;17(1):32.

25. Centers for Disease Control and Prevention. Health-related quality of life. 2017; https://www.cdc.gov/hrqol/. Accessed 10 Jan 2017.

26. Kaplan RM, Bush JW. Health-related quality of life measurement for evaluation research and policy analysis. Health Psychol. 1982;1 (1):61-80.

27. Smith TW, Marsden P, Hout M, et al. General Social Surveys, 2002, 2006, 2008, \& 2014 [machine-readable data file]. https://gssdataexplorer.norc.org.

28. Smith TW. The general social surveys: GSS project report no. 32. Chicago: NORC at the University of Chicago; 2016.

29. Centers for Disease Control and Prevention. How Does CDC Measure Population Health-Related Quality of Life? 2018; https://www.cdc.gov/hrqol/ methods.htm\#2. Accessed 22 Dec 2018.

30. Andresen EM, Fouts BS, Romeis JC, et al. Performance of health-related quality-of-life instruments in a spinal cord injured population. Arch Phys Med Rehabil. 1999;80(8):877-84

31. Newschaffer CJ. Validation of the BRFSS HRQOL measures in a statewide sample. Atlanta: U.S. Department of Health and Human Services, CDC; 1998.

32. Andresen EM, Catlin TK, Wyrwich KW, et al. Retest reliability of surveillance questions on health related quality of life. J Epidemiol Community Health. 2003;57(5):339-43.

33. Ligon E. GSS Methodological Report No. 64: The development and use of a consistent income measure for the General Social Survey. National Opinion Research Center, The University of Chicago. [1989] 1994.

34. Glanville IL, Andersson MA, Paxton P. Do social connections create trust? An examination using new longitudinal data. Social Forces. 2013;92(2):545-62.

35. Putnam RD. Bowling alone: the collapse and revival of American community. New York: Simon and Schuster; 2000. p. 249-310.

36. Baron RM, Kenny DA. The moderator-mediator variable distinction in social psychological research: conceptual, strategic, and statistical considerations. J Pers Soc Psychol. 1986;51 (6):1173-82. 
37. Haren MT. Abdominal adiposity and obstructive airway disease: testing insulin resistance and sleep disordered breathing mechanisms. BMC Pulm Med. 2012;12:31

38. Lumley $\mathrm{T}$, Diehr $\mathrm{P}$, Emerson $\mathrm{S}$, et al. The importance of the normality assumption in large public health data sets. Annu Rev Public Health. 2002; 23(1):151-69.

39. Doran T, Fullwood C, Kontopantelis E, et al. Effect of financial incentives on inequalities in the delivery of primary clinical care in England: analysis of clinical activity indicators for the quality and outcomes framework. Lancet. 2008;372(9640):728-36.

40. Elo IT. Social class differentials in health and mortality: patterns and explanations in comparative perspective. Annu Rev Sociol. 2009;35:553-72.

41. Johnson W, Krueger RF. How money buys happiness: genetic and environmental processes linking finances and life satisfaction. J Pers Soc Psychol. 2006:90(4):680-91.

42. Lachman ME, Weaver SL. The sense of control as a moderator of social class differences in health and well-being. J Pers Soc Psychol. 1998;74(3):763-73.

43. Kraus MW, Keltner D. Signs of socioeconomic status a thin-slicing approach. Psychol Sci. 2009;20(1):99-106.

44. Ziersch AM, Baum FE, MacDougall C, et al. Neighborhood life and social capital: the implications for health. Soc Sci Med. 2005;60(1):71-86.

45. Kawachi I, Berkman LF. Social ties and mental health. J Urban Health. 2001; 78(3):458-67.

46. Stafford M, Marmot M. Neighborhood deprivation and health: does it affect us all equally? Int J Epidemiol. 2003;32(3):357-66.

47. Stafford M, De Silva M, Stansfeld S, et al. Neighborhood social capital and common mental disorder: testing the link in a general population sample. Health Place. 2008;14(3):394-405.

48. Belle DE. The impact of poverty on social networks and supports. Marriage Fam Rev. 1983:5(4):89-103.

49. Liem R, Liem J. Social class and mental illness reconsidered: the role of economic stress and social support. J Health Soc Behav. 1978;19:139-56.

50. Durkheim E. Suicide: a study in sociology. (translated by John a. Spalding and George Simpson). London: Routledge \& Kegan Paul; 1970.

Ready to submit your research? Choose BMC and benefit from:

- fast, convenient online submission

- thorough peer review by experienced researchers in your field

- rapid publication on acceptance

- support for research data, including large and complex data types

- gold Open Access which fosters wider collaboration and increased citations

- maximum visibility for your research: over $100 \mathrm{M}$ website views per year

At $\mathrm{BMC}$, research is always in progress.

Learn more biomedcentral.com/submissions 